\title{
STATEMENT OF THE OPTIMIZATION PROBLEM OF CARBON PRODUCTS PRODUCTION
}

\author{
Zhuchenko O.A., PhD, Associate Professor ${ }^{1}$ \\ ${ }^{1}$ National technical university of «Kiev polytechnical institute», Kiev \\ ${ }^{1}$ E-mail: azhuch@ukr.net \\ ${ }^{1}$ ORCID: 0000-0001-5611-6529
}

Copyright (C) 2014 by author and the journal "Automation technological and business - processes". This work is licensed under the Creative Commons Attribution International License (CC BY). http://creativecommons.org/licenses/by/4.0/

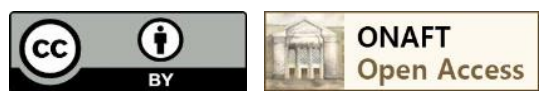

\section{DOI: $10.15673 /$}

\section{Abstract}

The paper formulated optimization problem formulation production of carbon products. The analysis of technical and economic parameters that can be used to optimize the production of carbonaceous products had been done by the author. To evaluate the efficiency of the energy-intensive production uses several technical and economic indicators. In particular, the specific cost, productivity, income and profitability of production. Based on a detailed analysis had been formulated optimality criterion that takes into account the technological components of profitability. The components in detail the criteria and the proposed method of calculating non-trivial, one of them - the production cost of each product. When solving the optimization problem of technological modes of production into account constraints on the variables are optimized. Thus, restrictions may be expressed on the number of each product produced. Have been formulated the method of calculating the cost per unit of product. Attention is paid to the quality indices of finished products as an additional constraint in the optimization problem. As a result have been formulated the general problem of optimizing the production of carbon products, which includes the optimality criterion and restrictions.

Key words

Carbon products, optimization problem, optimization criterion, cost, energy consumption, product quality.

\section{Introduction}

Development and deployment of innovative technologies in case of production of electrode products is caused of an actual task of decrease in specific costs of energy and material resources in engineering procedures such, as, actually productions of coal-graphite products, and when using of the called products in steel-smelting, ferroalloy arc furnaces of metallurgical and machine-building enterprises, anodes of magnesian electrolyzers, cathodes of aluminum electrolyzers, linings of blast, ferroalloy furnaces and electrothermal aggregates of the chemical industry, other equipment of a special functional purpose with special requirements to physical and chemical and mechanical properties of materials.

Metallurgical branch of Ukraine spend about 30\%of all power consumption at industries. Energy part of metallurgical products cost price is about $60 \%$, and at the same time this index is less than $25 \%$ at the advanced countries.

That is, the decision and implementation in production of new criteria of optimization of production it is directed to achievements of the European and international standards, promotes increase, first of all, in production competitiveness in Ukraine to electrode products, strengthening of strategic and important sectors of domestic economy and scientific technical development of technology of carbon and graphite and electrometallurgical production. On the other hand, the entity place in the world and domestic markets, an orientation on implementation of innovative developments, internal monitoring on reduction of specific costs of energy, product cost promotes investment appeal of the metallurgical entities of Ukraine.

Criteria choosing of manufacture optimization of carbon products.

To rate effectiveness of such energy intensive manufacture like carbon products production may be used some technic technical-and-economic indexes. Let's consider the most used of them.

The productivity of production, as a rule, is included to other indexes as its part, but it also may be an independent criteria. The productivity as an independent criteria is generally used if the methods are used to solve the optimization problems the productivity as a result becomes better and other indexes of economics don't become worse. 
Specific prime cost, as an index of effectiveness is generally used in case the optimal productivity by the criteria is not less than productivity, that is needed for timely qualified and full processing of all number initial raw materials.

The typical feature of specific prime cost, as a criteria of productivity effectiveness is an artificial reduction of a part, that can be calculated by specific exploration indexes. It occurs when the price of raw materials is permanent or its change is not connected with change of operational indicators and the mode of production. Therefore to estimate its efficiency it is reasonable to apply criterion of products prime cost unlike criterion of directly production cost on condition of change of prime cost of raw materials.

Profit of production - is an index of efficiency of production, that contains exploration cost, prime cost of raw materials and final product.

The most general performance indicator of production which consists of the above-considered indicators is profitability of sold goods which in a complex reflects efficiency rate of use of material, labor and money resources, and also natural riches [1]. Therefore exactly it is reasonable to choose this indicator as optimality criterion of production of carbon products.

The profitability of sold goods is calculated by the equation

$$
R_{Q}=\frac{Q}{C}
$$

where $Q$ - is profit of sailed products; $C \quad$ - prime cost of products.

Profit of sailed products is calculated by equation below:

$$
Q=\sum_{i=1}^{N} a_{i} F_{i},
$$

where $a_{i}$ and $F_{i}$ - is according to the price of a unit and the number of units of $i$ type of production; $N$ - the number of types of sailed production.

It is understood, that the value of profit is depended of a price and the number of sailed production of each type. In dependence of these indexes the value of profitability $Q$ will be changed.

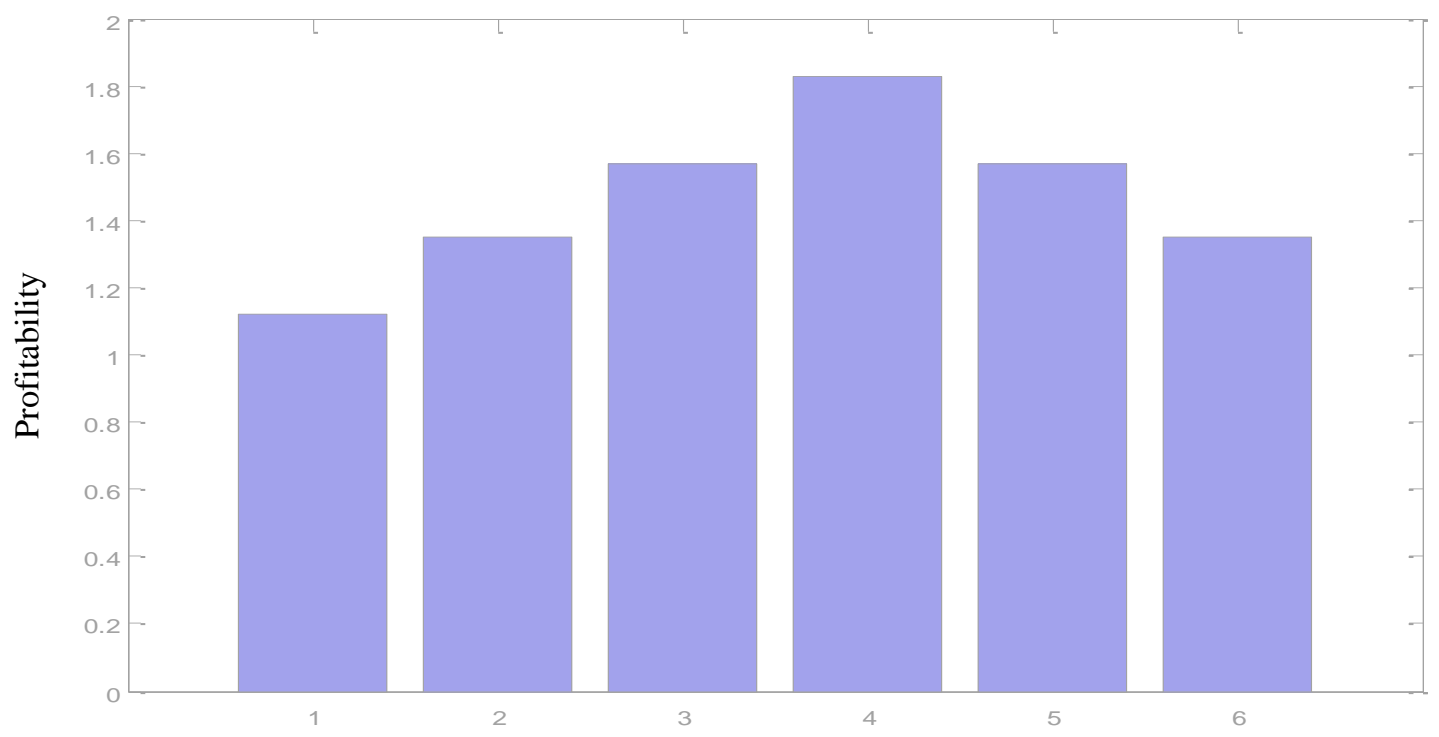

Number of batch

Fig. 1 - Profitability changing

At the fig. 1 it is shown the sailed products profitability changing of 6 various lots of carbon products for the same period of time on condition of the products general weight approximate invariance.

When prices and demand changes on the sales market the production effectiveness, that is evaluated by the profitability

$Q$, will be changed. It is caused the requirement of taking into account these changings in planning the production.

Let's consider the components of profitability more detailed.

The prime cost $C$ of the products consist of exploration costs $C_{E K}$ and initial raw materials $C_{\text {cup }}$ price.

$$
C=C_{E K}+C_{c u p}
$$


Raw materials costs in condition of defined volume of production is demands only of its price, but even if they are changed the costs are not depend on exploration indexes and the work modes of production. Taking into account this component to equation of criteria (1) brings to artificial reduction of component, that is defined by exploration indexes of production. That's why deciding optimization problems production technical areas works when the goal is to rise sensitivity of optimization criteria (1) to exploration indexes of production in calculation of prime cost $C$ of products manufacture by the equation (2), the component $C_{\text {cup }}$ should be neglected.

Exploration costs $C_{E K}$ are defined by energy- $\mathrm{M}$ and labor - $\mathrm{L}$ costs on technical processes of production:

$$
C_{E K}=M+L .
$$

Energy costs on production includes energy costs on its each area

$$
M=\sum_{j=1}^{s} m_{j},
$$

where $m_{j}$ - energy costs of $\mathrm{j}$ area of production; $S$ - a number of production areas.

Labor costs on production technical processes are calculated by the equation:

$$
L=L_{1}+L_{2}+L_{3},
$$

where $L_{1}$ - direct labor costs, $L_{2}$ - labor shop costs (the salary of labor shop personnel, amortization costs, labor rooms keeping and so on); $L_{3}$ - plant general costs (general plant personnel salary, plant laboratories keeping and so on).

Labor cost $L$ is not depended of technological modes of production processes and approximately is a constant value, that makes it possible not to consider it in optimal production processes modes calculation.

Based on the stated analysis above to solve optimization problem of production engineering procedures instead of criterion (1) it is reasonable to use its modified option:

$$
R=\frac{Q}{C_{E K}} .
$$

The usage of this criteria instead of (1) provides to rise sensitiveness of optimization criteria on the relation to the technological variables, which if are realized on the controlled object can provide its functioning in optimal technological mode.

Prime cost of exploration $\operatorname{costs} C_{E K}$ is calculated by the equation

$$
C_{E K}=\sum_{i=1}^{N} c_{i} F_{i},
$$

where $c_{i}$ - unit prime cost of $I$ type of product.

Technique of calculation of unit prime cost of $i$ products type.

The value $C_{i}$ in conditions of production, as a rule, is not the known size. Therefore the following methods of calculation of this size are offered.

The first can be used when for the fixed calendar period the known raw and energy production costs, and also amount of the made products in weight expression. In this case it is rather simple to calculate prime cost value of one kilogram of the made products. Having increased this result by the weight of each separate product, we get required prime cost value.

Unfortunately, this method, though formally answers the question posed, but actually does not give the objective answer to a question about prime cost value of each type of products separately because its application practically equalizes resourceand energy costs of all types of products that does not answer reality.

Other method provides the following technique of calculations. First of all it is necessary to determine real costs $S_{i}$ for each separate i products type:

$$
S_{i}=\sum_{j=1}^{n_{i}} S_{j},
$$

where $S_{j}$ - cost of $j$ component in $i$ products type; $n_{i}$ - a quantity of raw components in $i$ products type.

Further it is necessary to determine an energy component a prime cost value component i products. This task is more difficult. The reason consists that coal-graphite production is discrete and continuous, that is the basic power-intensive engineering procedures, such as a burning out and graphitizing, are made in the continuous mode, but products are processed by batches. At the same time the structure of the loaded products can be a miscellaneous from a batch to a batch. However completion of $m$ engineering procedure of handling only total energy costs $E_{l, m}$ on all $l$ batch are known which can be presented in the form 


$$
E_{l, m}=\sum_{i=1}^{N_{l}} e_{m, i} F_{i},
$$

where $e_{m, i}$ - processing costs of $i$ product in $m$ engineering procedure; $N_{l}$ - a quantity of different types of products in $l$ handling batch.

Having carried out enough campaigns of handling, we will receive the system of the linear algebraic equations of type (10) for $l=1,2 \ldots, N_{\mathrm{m}} . N_{\mathrm{m}}$ - the number of the campaigns of m engineering procedure. The decision of this system will give $e_{m, i}$. Having summed up, - quantity of technological production stages i - го a product; we will find energy costs.

Let's find energy costs $E_{i}$ on i products type.

General prime cost value of $i$ type of products is calculated as the amount of raw and energy costs:

$$
C_{i}=S_{i}+E_{i}, i=1,2, \ldots, \mathrm{N}
$$

where $N$ - total quantity of products.

Technological restrictions and quality of finished goods.

Solving a optimization problem of the production technological modes it is necessary to consider restrictions for variables which are optimized. On production of carbon products restrictions can be formulated differently.

Restrictions can be expressed by quantity of each type of the made products:

$$
F_{i} \leq F_{i}^{\max },
$$

where $F_{i}^{\text {max }}$ - the maximum productivity of production on $i$ products type.

Restriction which integrates in itself all types of products can be formulated thus:

$$
\sum_{i=1}^{N} g_{i} F_{i} \leq G_{\max },
$$

where $g_{i}$ - weight of $i$ products type; $G_{\max }$ - the maximum power of production, expressed in weight units.

Thus, the optimization problem of the technological modes of production mathematically includes an optimality criterion (7) with restrictions (11) and (12). This task is a task of integer nonlinear programming which can be solved by the known methods [2, 3], using the standard software [4].

This problem of nonlinear programming can be solved in 2 stages with use of methods [5, 6] and software [4] of linear programming.

It is for this purpose offered to solve two separate problems of linear programming at the first stage. The first task is formulated thus:

$$
Q=\sum a_{i} F_{i} \rightarrow \max
$$

in case of restriction of either (11), or (12) type. We will have decisions, as a result, which answer the maximum profit on sales of products in the conditions of restrictions for production power.

The second task of linear programming is formulated thus:

$$
C_{E K}=\sum_{i=1}^{N} c_{i} F_{i} \rightarrow \text { min }
$$

if limits are

$$
F_{i} \geq F_{i}{ }^{\mathrm{min}}, i=1,2, \ldots, N
$$

or

$$
\sum_{i=1}^{N} g_{i} F_{i} \geq G_{\text {min }},
$$

where $F_{i}{ }^{\text {min }}$ - minimum admissible quantity of the made products of $i$ type; $G_{\text {min }}$ - minimum admissible power of production in weight units.

The value $G_{\min }$ can be defined by this equation

$$
G_{\text {min }}=G_{\max }-\Delta,
$$

where $\Delta$ - the size of admissible reducing general production value known beforehand.

As a result of the solution of other task we have $F_{i}{ }^{I I} \quad i=1,2, \ldots, N$, those correspond to minimization of production operating costs. 
At the second stage it is necessary to scan ranges from $F_{i}{ }^{I}$ to $F_{i}{ }^{I I}$ to define optimum values $F_{i}{ }^{o p t}, i=1,2, \ldots, N$ as a result.

In case of certain quantity $n_{i}$ of $i$ products type need be surely produced the numerator and a denominator of expression (7) changes as appropriate:

$$
Q=\sum_{i=1}^{n} a_{i} n_{i}+\sum_{i=n+1}^{N} a_{i} F_{i},
$$

$$
C_{E K}=\sum_{i=1}^{n} c_{i} n_{i}+\sum_{i=n+1}^{N} c_{i} F_{i},
$$

where $n$ - a quantity of types of products which production volume is fixed.

At the same time the quantity of variables which are subject to search by production optimization decreases on $n$, that definitely simplifies a task.

Except the restrictions called above, it is necessary to consider restrictions for quality indicators of carbon and graphite products. These restrictions in general can be formulated as follows: $G_{\min } \leq G_{\text {fact }} \leq G_{\max }$,

where $G_{\mathrm{m} \text { in }}, G_{\mathrm{fact}}, G_{\mathrm{max}}$ - vectors of respectively minimum admissible, actual and most admissible values of quality indicators of carbon and graphite products. These vectors can consist[7-9]: for carbon blocks - density, porosity, strength limiton compression, temperature coefficient of linear expansion, heat conductivity coefficient; for graphite electrodes - the volume density, content of cindery impurity, specific electric resistance, thermal coefficient of linear expansion, a limit of mechanical durability on a bend, the module of rigidity of Jung.

Thus, increase of production efficiency of carbon products is connected with optimization of the modes of technological processes functioning on the basis of criterion (7) taking into account technological restrictions and increase of the necessary qualitative indexes of finished goods.

The solution of a optimization problem shall be performed before the next calendar period. Besides, the need for the repeated solution of this task can arise in case of not planned, or emergency stop of production, for example, in case of power supply shutdown.

\section{Conclusions}

On the basis of the analysis of technical and economic indicators which can be used for optimization of production of carbon products the optimality criterion which considers technological components of profitability of production is formulated. Components of the chosen criterion are in details considered and the uncommon calculation procedure is offered, to one of them - prime cost of production of each type of products.

Technological limits of production which can be considered solving optimization problem are formulated and the method of its considering is offered.

The attention is paid to qualitative indexes of finished goods as to additional restrictions in an optimization task.

The general optimization problem of production of carbon products which includes optimality criterion and restrictions is as a result formulated.

It is necessary to develop mathematical models of engineering procedures of production, and also system of their management for the solution of an objective, as is a subject of further researches.

\section{Resourses}

[1] Mytrofanova H. V., Kravchenko H. O., Barabash N. S. Finansovyi analiz /za red. H. V. Mytrofanova. - K.: Kyiv. nats. torh.-ekon. un-t: / Navchalnyi posibnyk - 2002. - 301 s.

[2] Box George E. R., Jenkins Gwilym M. Time series analysis, forecasting and control. Holden-day, Inc., 1976.

[3] Eikkhoff P. Osnovy ydentyfykatsyy system upravlenyia: otsenyvanye parametrov y sostoianyia / Eikkhoff P. - M. : Myr, 1975. $-683 \mathrm{~s}$.

[4] Gilat, Amos (2004). MATLAB: An Introduction with Applications 2nd Edition. John Wiley \& Sons. ISBN 978-0-47169420-5.

[5] Bertsekas, Dimitri P. (1999). Nonlinear Programing (Second ed.). Cambridge, MA.: Athena Scientific. ISBN 1-886529-000 .

[6] Ruszczyński, Andrzej (2006). Nonlinear Optimization. Princeton, NJ: Princeton University Press. pp. xii+454. ISBN 9780691119151.

[7] DSTU 4494:2005 Elektrody zghrafitovani ta nipeli do nykh. Zahalni tekhnichni umovy. Zi zminoiu № 1 (IEC 60239:1997, NEQ)

[8] Chalykh E. F. Tekhnolohyia y oborudovanye elektrodnykh y elektrouholnykh predpryiatyi / E. F. Chalykh. - M. : Metallurhyia, 1972. - $432 \mathrm{~s}$.

[9] Proyzvodstvo elektrodnoi produktsyy / [A. K. Sannykov, A. B. Somov, V. V. Kliuchnykov y dr.]. — M. : Metallurhyia, 1985. - $129 \mathrm{~s}$. 